\title{
Continuous axillary brachial plexus block
}

Tsuneo Sada MD, Tsutomu Kobayashi MD, Seiitsu Murakami MD

Continuous axillary brachial plexus block was performed in 597 patients undergoing prolonged operations on the hand. The technique required placement of a $5 \mathrm{~cm}$ 23 gauge tefton intravenous catheter in the axillary perivascular sheath. Lidocaine 1.5 per cent or mepivicaine 1.5 per cent (20-40 mi) were used for the initial block dose. Surgery was completed in 77.2 per cent of patients (460) with the axillary block alone while in 19.1 per cent of patients (114) supplementary narcotic administration or adititional regional blocks were required. In 3.7 per cent of patients (22) the technique was considered a complete failure. Complications included local anaesthetic toxic reactions (2.85 per cent, 17 cases), nerve injury (0.50 per cent, three cases) and one case of major haematoma formation. The advantages of this technique and the possible complications are discussed.

Key words ANAESTHETIC TECHNIQUES: regional, continuous axillary block.

From the Department of Anaesthesiology, School of Medicine, Kanazawa University.

Address correspondence to: Dr. T. Sada, Department of Anaesthesiology, Kanazawa University School of Medicine, 13-1 Takaramachi, Kanazawa, Ishikawa, Japan.
Reimplantation of severed fingers has become possible with use of the surgical microscope. Consequently, the duration of some operations has become more extended. Although the axillary approach to the brachial plexus is a recognized anaesthetic technique for operations on the upper extremities, the block by single dose injection has a time limit. If extension of the axillary block were possible, it might be a suitable technique for long-lasting operations

The old concept to the axillary approach ${ }^{1}$ by which individual nerves are blocked separately has been changed to a new one ${ }^{2}$ by which a large volume of local anaesthetic solution is deposited in a perivascular sheath, where it can diffuse easily to the median, radial and ulnar nerves with one single injection.

Adopting this new concept which eliminates the disadvantage of the single dose injection of the axillary brachial plexus block, we have used the simple technique of continuous axillary brachial plexus block, ${ }^{3}$ to facilitate reinjection of local anaesthetic by placing a teflon catheter within the axillary perivascular sheath. Our experience with the use of this technique in 597 patients is reported.

\section{Procedure}

The patient is placed in the recumbent supine position with or without a pillow. The upper extremity is abducted to 90 degrees and externally rotated 180 degrees; the forearm is flexed at the elbow. An " $X$ " is marked at the point where the pulsation of the brachial artery disappears under the pectoralis major muscle (Figure 1). The arm is then aseptically prepared and draped. A skin wheal is raised at the point marked " $X$." While palpating the pulsation of the brachial artery with the left index finger, a 23 gauge, $5 \mathrm{~cm}$ intravenous tefion catheter* is inserted at the " $\mathrm{X}$," pointing towards the apex

*Hakko elaster consists of an inner 23 gauge $5.2 \mathrm{~cm}$ needle and an outer 19 gauge $5.0 \mathrm{~cm}$ teflon catheter. Hakko Shoji Limited, 14-11 Ueno 5-Chome, Taito-ku, Tokyo, Japan. (Medicut or Angiocath may also be used.) 


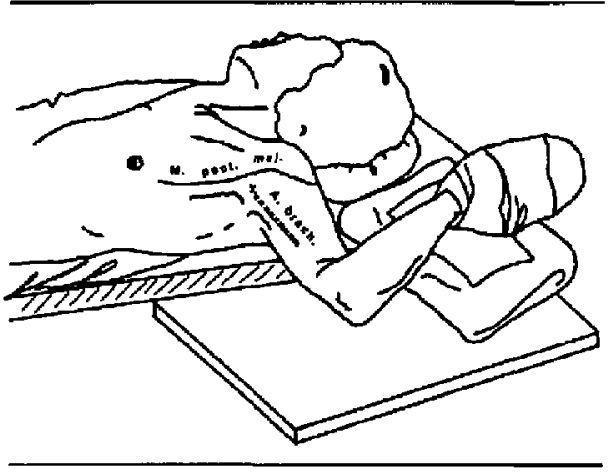

FIGURE 1 Point of catheter insertion ("X") where pulsation of brachial artery disappears under pectoralis major muscle.

of the axilla at an angle of about 20 degrees with the skin (Figure 2). The catheter is advanced slowly until a distinct "click" is obtained or a paraesthesia is elicited. At this point arterial pulsations are normally transmitted to the catheter. In our experience, a paraesthesia is a better sign than the "click" in establishing that the catheter tip is within the perivascular sheath. The outer teflon catheter alone is advanced up to the hub (Figure 3 ). After the inner needle is withdrawn, a $30-40 \mathrm{~cm}$ long intravenous extension tube is connected to the catheter to facilitate repeated injections, at a distance from the puncture site. A three-way stopcock is connected to the free end of the extension tube. The puncture site is covered with a sterilized sponge and the catheter, sponge and extension tube are fixed to the skin with Steri-Strips ${ }^{\oplus}, *$ and then covered with a SteriDrape ${ }^{2} \dagger$ or Mepore ${ }^{6} \ddagger$ (Figure 4). Five milliliters of bupivacaine is infiltrated subcutaneously around the medial aspect of the proximal one third of the upper arm to block the intercostobrachial nerve which does not lie in the perivascular sheath (Figure 4). After repeated aspiration tests, lidocaine 1.5 per cent (or mepivacaine 1.5 per cent) 20 to $40 \mathrm{ml}$ is injected through the three-way stopcock.

\section{Case reports}

The following three case reports illustrate our use of

*Steri-Strip: Surgical Products Division 3M Company, St. Paul, Minnesota 55101, U.S.A.

†Steri-Drape: Surgical Products Division 3M Company, St. Paul, Minnesota 55101, U.S.A.

‡Mepore: Mölnlycke, S-43501 Mölnlycke, Sweden.

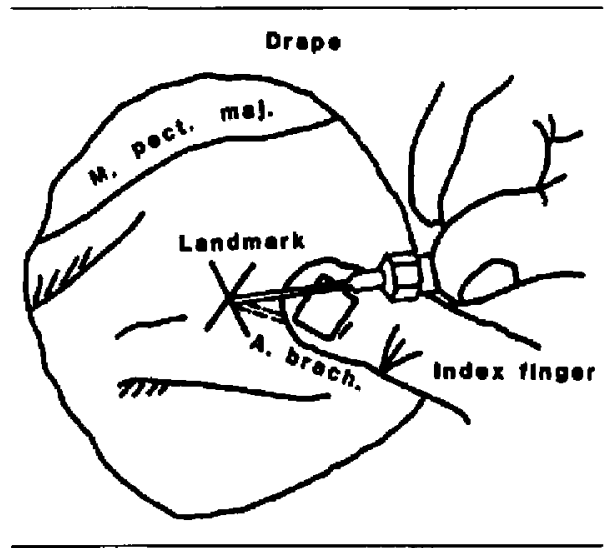

FIGURE 2 Intravenous catheter inserted at " $\mathrm{X}$," pointing towards apex of axilla, at an angle of about 20 degrees to the skin.

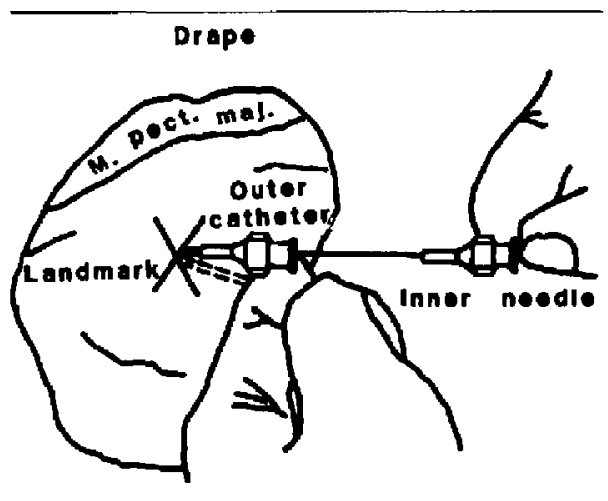

FIGURE 3 Adyancement of outer teflon catheter.

the continuous axillary block technique. Our use of the technique in 597 patients is summarized.

\section{Case 1}

A 43-year-old man's right hand was injured by a paper cutter. The index, middle and ring fingers were incompletely amputated and the little finger completely severed two hours before admission. Reconstructive surgery, including tendon and nerve suture and anastomoses of blood vessels was planned for each finger. Continuous axillary brachial plexus block was chosen as the anaesthetic technique. After obtaining a paraesthesia of the median nerve, $30 \mathrm{ml}$ of mepivacaine 1.5 per cent 


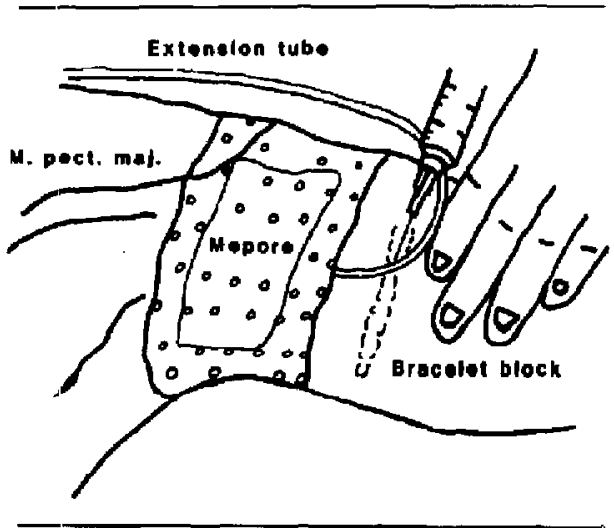

FIGURE 4 Secured catheter. Inscrtion of "Bracelet Block." See Text.

was injected as an initial dose. Fifteen minutes later, complete analgesia and paralysis of the right arm had become established

Diazepam $(5 \mathrm{mg})$ was given intravenously before the block for sedation and prevention of a systemic local anaesthetic toxic reaction. Mepivacaine 1.5 per cent and bupivacaine 0.5 per cent were alternatively injected through the catheter during the operation and additional doses of diazepam were given intravenously as necessary. The total doses of mepivacaine, bupivacaine and diazepam used were 1050,100 and $35 \mathrm{mg}$ respectively during the 12-hour operation. The operative and postoperative courses were uneventful.

\section{Case 2}

A 49-year-old woman's right hand was caught in a press machine and the index, middle, ring and little fingers were severed. Reimplantation of the four amputated fingers was undertaken under continuous axillary brachial plexus block.

Following the intravenous administration of $5 \mathrm{mg}$ of diazepam, $30 \mathrm{ml}$ of lidocaine 1.5 per cent was injected as the initial dose. After the block had become established, another $5 \mathrm{mg}$ of diazepam was given intravenously. One hour after the initial injection, $10 \mathrm{ml}$ of bupivacaine 0.5 per cent was injected as the second dose. Thereafter $10 \mathrm{ml}$ of bupivacaine 0.5 per cent was injected every three to four hours. Additional doses of diazepam were given as necessary.

The total doses of lidocaine, bupivacaine and diazepam used were 450,250 and $40 \mathrm{mg}$ respectively for the 17-hour operation. The patient tolerated the procedure well and was sent to the ward immediately afterwards without complications.

\section{Case 3}

A 20-year-old man who had lost his left thumb in an accident two years earlier was admitted to have the second toe of his right foot transplanted to the left thumb for cosmetic and functional purposes.

Subarachnoid block was performed with dibucaine, to anaesthetize the foot, following which a catheter was placed in the axillary perivascular sheath. Forty milliliters of mepivacaine 1.5 per cent was injected as the initial dose. Mepivacaine 1.5 per cent and bupivacaine 0.5 per cent were used for subsequent injections. Diazepam was given intravenously as required. Total doses of mepivacaine, bupivacaine and diazepam were 1200, 200 and $20 \mathrm{mg}$ respectively for the nine hours of operation.

Our experience from 1974 to 1981 with the use of the continuous axillary brachial plexus block technique in 597 patients is summarized in Table $I$. Surgery was completed in 77.2 per cent (461) of patients with the use of the continuous axillary block alone (full success). In 19.5 per cent (114) of patients, supplementation of the axillary block (intravenous narcotics, additional nerve block or wound infiltration with local anaesthetics) was required, but surgery was completed without the need to resort to general anaesthesia (partial success). The technique was considered a failure in 3.7 per cent (22) of patients when surgery could not be completed without general anaesthesia.

Complications encountered included systemic toxic reactions in 17 patients ( 2.85 per cent), three nerve injuries ( 0.5 per cent) and one significant haematoma, compromising circulation to the arm.

\section{Discussion}

We suggest the following advantages for the continuous axillary brachial plexus technique, in addition to the facilitation of surgery of long duration: (1) sympathetic nerve block and vasodilation, (2) the muculocutaneous nerve is usually blocked by this technique although the standard axillary approach sometimes fails to block this nerve, (3) accidental intravascular injection is prevented, because the catheter is fixed, (4) the catheter is available for use in the treatment of postoperative pain. 
TABLE I Summary of experience

\begin{tabular}{lcccc}
\hline & & $\begin{array}{l}\text { Full } \\
\text { Success }\end{array}$ & $\begin{array}{l}\text { Parial } \\
\text { Success }\end{array}$ & Failure \\
\hline 1974 & 8 & 4 & 4 & 0 \\
1975 & 53 & 42 & 10 & 1 \\
1976 & 62 & 41 & 17 & 4 \\
1977 & 66 & 48 & 14 & 4 \\
1978 & 70 & 61 & 8 & 1 \\
1979 & 110 & 83 & 23 & 4 \\
1980 & 120 & 100 & 18 & 2 \\
1981 & 103 & 82 & 20 & 6 \\
Total & 597 & 461 & 114 & 22 \\
& & $(77.2 \%)$ & $(19.1 \%)$ & $0.7 \%)$ \\
\hline
\end{tabular}

The key point to the success of the block is the placement of the catheter precisely in the axillary sheath. Burnham ${ }^{2}$ suggested that paraesthesia elicitation is not essential for this block. However, we still prefer to obtain a paraesthesia to confirm that the catheter is precisely placed in the sheath.

Haematoma formation, nerve injury, infection, and systemic toxic reactions to the local anaesthetics are possible complications of the technique. Puncture of the artery or vein should be avoided, because heparin is used during surgery. If vascular puncture occurs, direct compression of the puncture site and digital massage should be applied to prevent haematoma formation. Nerve injury is possible. ${ }^{4}$ Two of our three patients with postoperative evidence of nerve injury demonstrated abnormality in the radial nerve distribution. In neither case were radial nerve paraesthesias elicited during performance of the block. The third patient experienced a median nerve lesion, and in this patient a median nerve paraesthesia had been elicited. The possibility that the axillary block technique caused or contributed to this postoperative nerve lesion must therefore be considered.

Strict sterile technique during performance of the block should be maintained to prevent infection. We believe that use of a Steri-Drape ${ }^{\sqrt{6}}$ or Mepore ${ }^{\text {is }}$ a good technique, not only to immobilize the catheter and attached extension tube, but also to protect the puncture site from infection.

Since the perivascular technique was introduced, the amount of local anaesthetic solution used for this block has been increasing. ${ }^{2,5-7}$ We use $0.2 \mathrm{ml} / \mathrm{cm}$ height of lidocaine 1.5 per cent, or mepivacaine 1.5 per cent, as an initial dose and half of the initial dose as the subsequent dose. As the duration of operation becomes extended, larger amounts of anaesthetic solution are required. Thus, the local andesthetics may tend to accumulate, and the plasma level may be elevated, leading to systemic toxic reactions. To avoid this complication, we recommend: (1) elevate the threshold for systemic toxic reactions, (2) minimize the amount of local anaesthetics used.

Diazepam is known to be an effective agent for preventing local anaesthetic induced convulsions. ${ }^{8-10}$ We therefore recommend premedication with diazepam when large doses of local anaesthetics must be used. We administer $0.1 \mathrm{mg} / \mathrm{kg}$ of diazepam intravenously before the block, and another $0.1-0.2 \mathrm{mg} / \mathrm{kg}$ following establishment of the block. Additional $0.1 \mathrm{mg} / \mathrm{kg}$ doses are given to sedate the patient as necessary during the operation.

To minimize the amount of local anaesthetics, we prefer a long lasting agent. However, we use lidocaine 1.5 per cent (or mepivacaine 1.5 per cent) without vasoconstrictor, as an initial injection because bupivacaine has a somewhat slow onset. After the establishment of the block, bupivacaine 0.5 per cent is used for the repeated injections. However, in those cases where bupivacaine 0.5 per cent does not produce complete paralysis of the arm, lidocaine 1.5 per cent (or mepivacaine 1.5 per cent) is used because it is difficult to carry out a delicate operation under the surgical microscope when the patient moves his arm, hand or fingers.

In summary, we have managed 597 cases of upper extremity surgery using continuous axillary brachial plexus block, with a low incidence of serious complications. We propose this technique as an acceptable method of regional anaesthesia for protracted operations of the upper extremity.

\section{References}

1 Accardo NJ, Adriani J. Brachial plexus block: a simplified technique using the axillary route. South Med J 1949; 42: 920-3.

2 Burnham PJ. Regional block of the great nerves of the upper arm. Anesthesiology 1958; 19: 281-4.

3 Rosenblatt R, Pepitone-Rockwell F, McKillop MJ. Continuous axillary analgesia for traumatic hand injury. Anesthesiology 1979; 51: 565-6.

4 Selander $D$, Edshage $S$, Wolff $T$. Paresthesiae or no paresthesiae? Nerve lesions after axillary blocks. Acta Anesthesiol Scand 1979; 23: 27-33. 
5 Eather $K F$. Axillary brachial plexus block (correspondence). Anesthesiology 1958; 19: 683-5.

6 De Jong RH. Axillary block of the brachial plexus. Anesthesiology 1961; 22: 215-25

7 Winnie AP, Radonjic R, Akkineni SR, Durrani $Z$. Factors influencing distribution of local anesthetic injected into the brachial plexus sheath. Anesth Analg 1979; 58: 225-34.

8 Aldrete JA, Daniel $W$. Evaluation of premedicants as protective agents against convulsive $\left(L D_{50}\right)$ doses of local anesthetic agents in rats. Anesth Analg 1971; 50: 127-30.

9 De Jong RH, Heavner JE. Convulsions induced by local anesthetic: time course of diazepam prophylaxis. Can Anaesth Soc J 1974; 21: 153-8.

10 Ausinsh B, Malagodi MH, Munson ES. Diazepam in the prophylaxis of lidocaine scizure. Br J Anaesth 1976; 48: 309-13.

Résumé

Le bloc continuel du plexus axillaire a été pratiqué chez 597 patients subissant une opération prolongée de la main. Pour cette technique, nous avons placé un cathéter intraveineux en teflon de calibre 23 et long de $5 \mathrm{~cm}$ dans l'axillaire de l'espace perivasculaire. Une dose de 1.5 pour cent de lidocaine ou de mépivicaine 1.5 pour cent $(20-40 \mathrm{ml})$ a été injectée pour la dose initiale du bloc. L'opération chirurgicale fut complétée chez 77.2 pour cent des patients (460) avec le bloc axillaire seulement alors que chez 19.1 pour cent des patients (114), une administration supplementaire de narcotique fut injectée ou des blocs régionaux additionnels furent nécessaires. Dans le cas de 3.7 pour cent des patients (22), la technique fut considérée un échec total'. Les complications ont entraîné des réactions toxiques avec l'agent d'anesthésie locale (2.85 pour cent. 17 cas), des lésions aux nerfs ( 0.50 pour cent, 3 cas $)$ et un cas extréme de formation d'hématome. Les avantages de cette technique et les complications possibles sont discutées. 